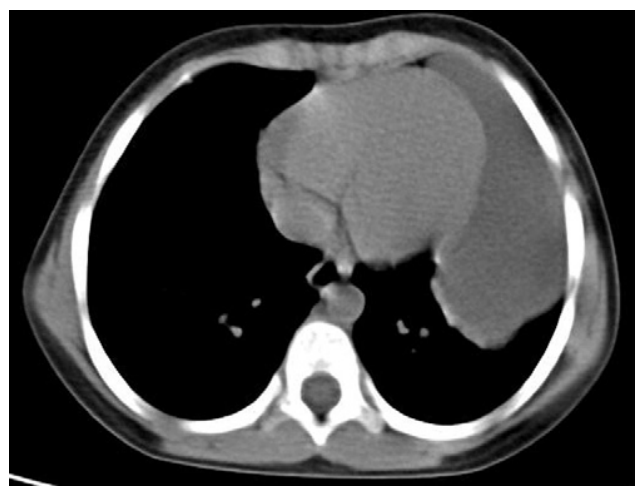

Figure 2. Computed tomographic scan of the chest revealing a large well-defined cyst in the left paracardiac region in close contact with pericardium and with pressure effect on the lower lobe.
Our patient had a large lymphangioma involving the anterior and middle mediastinum, which is unique inasmuch as isolated lymphangioma of the mediastinum in the pediatric population is exceedingly uncommon and there are only a few such reported cases. Complete resection of the cyst is the treatment of choice in these patients.

\section{References}

1. Feutz EP, Yune HY, Mandelbaum I, Brasher RE. Intrathoracic cystic hygroma: a report of three cases. Radiology. 1973;108:61-6.

2. Nansom EM. Lymphangioma (cystic hygroma) of the mediastinum. J Cardiovasc Surg (Torino). 1968;9:447-52.

3. Wright CC, Cohen DM, Vegunta RK, Davis T, King DR. Intrathoracic cystic hygroma: a report of three cases. J Pediatr Surg. 1996;31:1430-2.

4. Brown LR, Reiman HM, Rosenow EC 3rd, Gloviczki PM, Dirertie MB. Intrathoracic lymphangioma. Mayo Clin Proc. 1986;61:882-92.

5. Enzinger FM, Weiss SW. Soft tissue tumors. 4th ed. St Louis: Mosby; 2001. p. $955-83$

\title{
Transcervical intraluminal repair of posterior membranous tracheal laceration through semi-lateral transverse tracheotomy
}

In Kyu Park, MD, Jin Gu Lee, MD, Chang Young Lee, MD, Dae Joon Kim, MD, and Kyung Young Chung, MD, Seoul, Republic of Korea

\section{Clinical Summary}

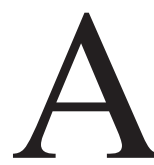

n 89-year-old female patient was admitted with pneumomediastinum in the left superior mediastinum on a chest radiogram after emergency orotracheal intubation in the emergency room. She was intubated owing to respiratory arrest after administration of sedatives to obtain a computed tomogram (CT) of the brain for evaluation of brain injury. She had arrived at the hospital with multiple injuries to the face and head in a stuporous mental status. The exact cause and vector of trauma were unknown. She had a history of dementia.

From the Department of Thoracic and Cardiovascular Surgery, Yonsei University College of Medicine, Seoul, Republic of Korea.

Received for publication June 13, 2007; revisions received Aug 1, 2007; accepted for publication Sept 5, 2007.

Address for reprints: In Kyu Park, MD, Department of Thoracic and Cardiovascular Surgery, Yonsei University College of Medicine, 250 Seongsanno, Seodaemun-gu, Seoul, Republic of Korea, 120-752 (E-mail: ik2653@yumc.yonsei.ac.kr).

J Thorac Cardiovasc Surg 2007;134:1597-8

$0022-5223 / \$ 32.00$

Copyright $\odot 2007$ by The American Association for Thoracic Surgery doi:10.1016/j.jtcvs.2007.09.001
Chest CT revealed tracheal rupture at the left posterolateral wall with subcutaneous emphysema, pneumomediastinum in the superior mediastinum, and pneumothorax on the left side. There was no abnormality on brain CT. On bronchoscopic scan, the trachea was lacerated longitudinally along the membranous and cartilage junction on the left. The distal end was $3 \mathrm{~cm}$ cephalad to the carina, but the proximal end was not defined. The balloon of the endotracheal tube was positioned distal to the laceration at the end of bronchoscopy.

After induction of general anesthesia, a cervical collar incision was made in the neck extension position. The left lateral wall of the trachea was dissected along the third and fourth tracheal cartilages. A tracheal laceration was found at the left posterior tracheal wall. The proximal end was at the level of fourth tracheal cartilage. The margin was sharp and clear. The distal end of the laceration was deep in the mediastinum because of the short, stiff neck. Transcervical extraluminal identification and repair of the laceration seemed impossible without a long segmental dissection of the trachea. To avoid extensive dissection and get appropriate access, we believed intraluminal repair through a tracheotomy to be the approach of choice.

A left semi-lateral transverse tracheotomy that connected to the laceration was made by a sharp blade to open the trachea in a reverse $\mathrm{L}$ shape. After retracting the corner of the reverse $\mathrm{L}$ with an anchoring suture, we could approach the whole laceration intraluminally (Figure 1). The laceration was about $4.5 \mathrm{~cm}$ long. It was repaired by interrupted $4-0$ absorbable monofilament sutures 


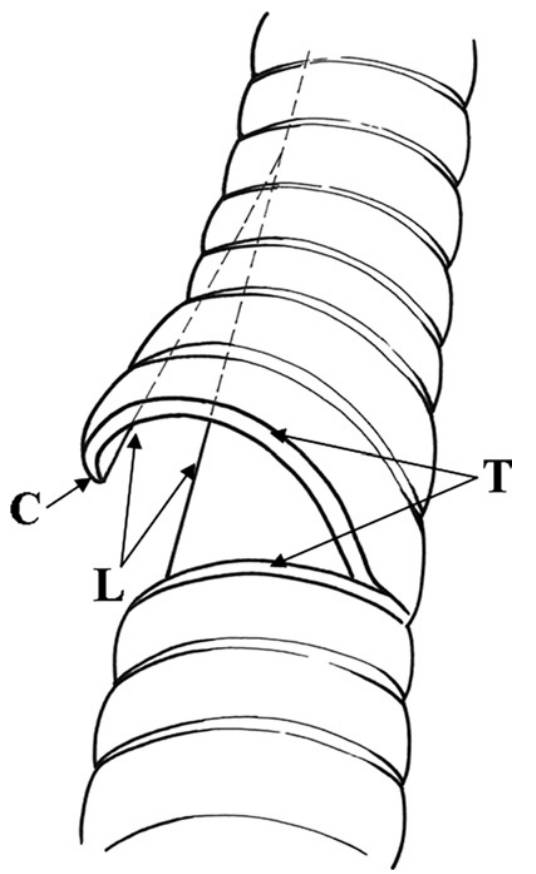

Figure 1. Semi-lateral transverse tracheotomy connected to membranous tracheal laceration. $L$, Both margins of laceration; $C$, corner of reverse $L ; T$, both margins of transverse tracheotomy.

after minimal dissection and trimming of the edge. For the repair of the distal $1 \mathrm{~cm}$, the endotracheal tube was withdrawn to the proximal end and ventilation was interrupted. After repair of the distal end, the endotracheal tube was reintroduced to the distal part of the laceration and ventilation was resumed to the end of the procedure without interruption. During repair of the remaining portion, the endotracheal tube was retracted in the opposite direction of the laceration. The tracheotomy was closed by interrupted sutures. The left sternohyoid muscle was interposed between the trachea and esophagus. Extubation was delayed until the third postoperative day because of atelectasis, respiratory difficulty, and delirium. After that she recovered uneventfully and was discharged 7 days later. Postoperative bronchoscopy was not performed, because we could find no benefit of performing a stressful procedure in an elderly patient with dementia without evidence in disruption or stenosis of the trachea.

\section{Discussion}

Almost any membranous tracheal laceration can be repaired by a transcervical approach. Transcervical extraluminal repair of the distal tracheal is technically difficult and sometimes requires sternotomy or right thoracotomy. ${ }^{1,2}$ Also, an extraluminal approach requires extensive dissection of peritracheal tissue, thus increasing the risk of interruption of lateral blood supply or injury of the recurrent laryngeal nerve. ${ }^{3,4}$ Several transtracheal methods have been reported, such as transtracheal endoluminal repair through a vertical tracheostomy, transverse anterior tracheotomy, T-shaped anterior tracheotomy, and tracheal transection. ${ }^{3-5}$ These methods have the benefit of preventing complications resulting from extensive dissection. However, the endoluminal approach is also technically complicated owing to limited accessibility and needs a relatively long tracheal injury and complex ventilation management such as repeated withdrawal of the endotracheal tube or intubation through the surgical field.

An intraluminal approach through a semi-lateral transverse tracheotomy can be done without extensive dissection of the trachea. The blood supply can be preserved and recurrent laryngeal nerve injury can be avoided as in endoluminal approaches. Furthermore, semi-lateral transverse tracheotomy requires a shorter tracheal incision and the risk of stenosis is lower. Access to the laceration is good and control of ventilation is simple. Just one episode of ventilatory interruption was needed for evaluation and repair of the distal end of the laceration with a regular-sized endotracheal tube. The mid-to-proximal part of the laceration and posterior portion of the tracheotomy could be repaired intraluminally with ease and good visibility by upward retraction of the endotracheal tube in the opposite direction of the laceration.

In conclusion, transcervical intraluminal repair through a semilateral transverse tracheotomy is another good method for treatment of membranous tracheal laceration, especially in long segmental lacerations involving the distal trachea.

\section{References}

1. Massard G, Rougé C, Dabbagh A, Kessler R, Hentz JG, Roeslin N, et al. Tracheobronchial laceration after intubation and tracheostomy. Ann Thorac Surg. 1996;61:1483-7.

2. Mussi A, Ambrogi MC, Menconi G, Ribechini A, Angeletti CA. Surgical approaches to membranous tracheal wall lacerations. $J$ Thorac Cadiovasc Surg. 2000;120:115-8.

3. Angelillo-Mackinly T. Transcervical repair of distal membranous tracheal laceration. Ann Thorac Surg. 1995;59:531-2.

4. Lancelin C, Chapelier AR, Fadel E, Macchiarini P, Dartevelle PG. Transcervical-transtracheal endoluminal repair of membranous tracheal disruption. Ann Thorac Surg. 2000;70: 984-6.

5. Carbognani P, Bobbio A, Cattelani L, Internullo E, Caporale D, Rusca M. Management of postintubation membranous tracheal rupture. Ann Thorac Surg. 2004;77:406-9. 